\title{
JOGOS OLÍMPICOS EM REVISTA: UM ESTUDO SOBRE A PARTICIPAÇÃO BRASILEIRA NOS JOGOS OLÍMPICOS (1968-1996)
}

\author{
Doiara Silva dos Santos \\ Universidade Federal de Juiz de Fora, Campus Avançado de Governador Valadares, Minas Gerais, \\ Governador Valadares, Brasil \\ Ana Gabriela Alves Medeiros \\ Universidade do Estado da Bahia, Bahia, Salvador, Brasil \\ Guilherme Ferreira Santos \\ Instituto Federal de Educação, Ciência e Tecnologia de Goiás, Goiás, Uruaçu, Brasil
}

\begin{abstract}
Resumo
O objetivo deste trabalho é analisar narrativas midiáticas sobre jogos olímpicos, a partir de reportagens da Revista Veja, de 1968 a 1996. Para tanto, utilizou-se como técnica a Análise de Conteúdo. Os seguintes eixos temáticos foram identificados e discutidos a partir das narrativas: 1) ser olímpico, referindo-se ao sentido da participação amadora dos brasileiros; 2) o clamor por atletas competitivos, correspondendo à cobrança por uma melhor organização e resultados esportivos; 3) de indigentes a heróis olímpicos - narrativas que apontam a mudança de papel na participação dos brasileiros, enfatizando os bons resultados.
\end{abstract}

Palavras-chave: Esporte. Mídia. Jogos Olímpicos.

\section{Introdução}

Com o direito garantido à cidade do Rio de Janeiro de sediar os Jogos Olímpicos de 2016, o interesse pela temática olímpica nos âmbitos acadêmico, social e midiático no Brasil tem se expandido. Entretanto, a atenção midiática brasileira ao evento é anterior à conquista do direito de sediar os Jogos e manifesta-se a partir de diferentes perspectivas ao longo da história.

O fenômeno esportivo, de maneira geral, tem ocupado espaço significativo nos mais diversos universos discursivos, embora, a princípio, tenha sido negligenciado como um tema "sério" no âmbito acadêmico. Tal negligência, como apontam DaMatta (2003), assim como Elias e Dunning (1992), é decorrente da predominância de uma ideologia social voltada para o trabalho, que privilegiou na pesquisa social temas como, por exemplo, a política e a economia.

À medida que se reconheceram, nas diversas manifestações do esporte, objetos de investigação importantes, o tema passou a ser abordado por diferentes áreas do conhecimento. Particularmente, no que se refere às abordagens socioantropológicas, as práticas e rituais esportivos (e isso inclui o contexto dos Jogos Olímpicos) têm sido "palco" para problematizar, compreender e interpretar "dramas sociais" de diversas sociedades (MacALOON, 1984).

O desenvolvimento das mídias e a consolidação dos Jogos Olímpicos ocorreram em 
uma relação de reciprocidade ao longo do século XX, num contexto de notáveis e complexas mudanças sociais e históricas em todo o mundo (BRIGGS; BURKE, 2004). Embora os grandes eventos esportivos tenham espaço considerável e de destaque na mídia nos dias atuais, os Jogos Olímpicos apresentam-se de maneira diferenciada - não apenas em relação às cifras que movimentam, mas, principalmente, em relação à dependência simbólica de tais meios para sua perpetuação e popularidade (SPÀ, 1990).

Um dos fatores que podemos mencionar para explicar a atenção e o locus de destaque alcançado pelos Jogos Olímpicos (JO) modernos nos diferentes âmbitos é o complexo constructo ideológico no qual estão envoltos. Esse constructo orienta a singular característica dos JO, compreendidos como uma "performance cultural" (MacALOON, 1984), que adquire uma configuração específica ao reunir, simultaneamente, dimensões muito particulares, a saber: 1) o espetáculo (tamanho e grandeza); 2) o ritual (celebração secular de valores da modernidade, a partir de cerimônias e solenidades); 3) o festival (no que se refere às mensagens de equilíbrio, harmonia, paz internacional e alegria); e 4) o jogo (a estrutura mais formal de dramatização da vida social).

Tais características atribuem um caráter distinto aos Jogos Olímpicos em relação a campeonatos mundiais e outras competições esportivas que, embora internacionais, não alcançam o envolvimento das massas em perspectivas globais com a mesma intensidade. A periodicidade do evento, ou seja, a olimpíada (o período quadrienal entre as edições dos Jogos) também emoldura o evento como um acontecimento nobre e/ou "raro" em relação aos demais. Logo, o evento tornara-se conteúdo atraente para as diferentes mídias, que dedicam atenção peculiar em relação ao acontecimento na produção de suas narrativas (MacALOON, 1984). Essa inter-relação entre os Jogos Olímpicos e a mídia constitui a temática central deste trabalho.

\section{Decisões metodológicas e objetivos}

Nesta seção, demarcam-se os procedimentos e decisões metodológicas que levaram ao desenho teórico e à formulação de questões e objetivos desta pesquisa. A partir do levantamento bibliográfico em periódicos brasileiros da Educação Física e outras áreas que tomam por objeto o fenômeno esportivo (as Ciências Sociais, por exemplo), pode-se perceber no corpus epistemológico sobre esporte, mídia e Jogos Olímpicos uma carência de estudos que utilizem fontes de mídia anteriores à primeira década dos anos 2000 e/ou final dos anos 1990. Tendo por base esta constatação, neste estudo, portanto, buscaremos analisar a temática olímpica na mídia impressa em períodos anteriores aos anos 2000.

Para demarcar o ponto inicial do recorte cronológico do presente estudo, elegemos um período histórico de transformações críticas na popularização dos Jogos Olímpicos: o final da década de 1960 e início da década de 1970. Podemos apontar duas razões principais para tanto: a primeira é que nesse período desenvolveu-se o aparato tecnológico necessário para a transmissão televisiva internacional dos Jogos Olímpicos, o que, portanto, contribuiu para a sua popularização e despertou interesse global sobre o evento (ver Tabela 1); e a segunda 
refere-se às iniciativas mais tangentes para disseminar o Movimento Olímpico na América Latina que abrangem esse período ${ }^{1}$.

Tabela 1 - Jogos Olímpicos de Verão: Países com cobertura televisiva Fonte: Olympic Marketing Fact File, International Olympic Committee, 2012

\begin{tabular}{|c|c|}
\hline Jogos Olímpicos & $\begin{array}{c}\text { Número de } \\
\text { países/ } \\
\text { Territórios com } \\
\text { cobertura } \\
\text { televisiva }\end{array}$ \\
\hline 1936 Berlim & 1 \\
\hline 1948 Londres & 1 \\
\hline 1952 Helsinki & 2 \\
\hline 1956 Melbourne & 1 \\
\hline 1960 Roma & 21 \\
\hline 1964 Tóquio & 40 \\
\hline 1968 Cidade do & $\begin{array}{c}\text { Dados não } \\
\text { disponíveis }\end{array}$ \\
\hline 1972 Munique & 98 \\
\hline 1976 Montreal & 124 \\
\hline 1980 Moscow & 111 \\
\hline 1984 Los Angeles & 156 \\
\hline 1988 Seul & 160 \\
\hline
\end{tabular}

A partir dessa constatação, escolhemos como fonte de análise a Revista Veja (RV). Tal revista é de circulação nacional e alcançou grande visibilidade no cenário brasileiro ao longo dos anos. Além disso, a referida fonte tem todo o seu acervo digitalizado, o que facilita o acesso aos dados necessários, tanto para a realização do estudo, quanto permite ao leitor consultá-los ${ }^{3}$.

A questão que orienta esta investigação é: quais as principais características do discurso midiático da Revista Veja sobre a temática olímpica das décadas de 1960 a 1990 ? Assim, temos por objetivos identificar e analisar as narrativas midiáticas sobre a temática olímpica a partir de matérias e/ou reportagens da Revista Veja publicadas a cada "ano olímpico" de 1968 a 1996, a fim de discutir as principais características do discurso midiático sobre os Jogos Olímpicos nesse período.

\footnotetext{
${ }^{1}$ Sobretudo, as iniciativas lideradas pela presidência do Comitê Olímpico Internacional, sob o comando de Avery Brundage, de 1952 a 1972 (GUTTMAN, 1984).

2 Primeira vez que os Jogos Olímpicos foram transmitidos ao vivo no Brasil.

${ }^{3}$ Destaca-se o fato de que a Revista, como quaisquer veículos midiáticos, tem influências e posicionamentos políticos no cenário nacional; não é o foco deste estudo abordá-las.
} 
Foram incluídas no corpus deste estudo matérias e/ou reportagens sobre os Jogos Olímpicos em geral, mas, o interesse central é sobre a cobertura da participação brasileira, publicados nos anos de competição: Jogos do México, 1968; Jogos de Munique, 1972; Jogos de Montreal, 1976; Jogos de Moscou, 1980; Jogos de Los Angeles, 1984; Jogos de Seul, 1988; Jogos de Barcelona, 1992; e Jogos de Atlanta, 1996.

Utilizamos como instrumento de coleta de dados uma ficha de catalogação para sistematizar o processo de análise, na qual estavam contidas: 1) informações gerais sobre a matéria/reportagem (data, edição, autoria e páginas); 2) informações específicas (ilustrações, tema, tamanho); bem como 3) citação de fragmentos na íntegra, extraídos das reportagens.

A discussão das informações obtidas fundamenta-se na Análise de Conteúdo qualitativa. Segundo Bauer e Gaskell (2002), a partir da análise retórica pode-se realizar a interpretação textual e social do evento discursivo para categorizar informações. Diante da recorrência temática, foram estabelecidas as categorias de análise: 1) "Ser Olímpico" refere-se ao sentido legitimado da participação "amadora" da equipe brasileira; 2) o clamor por atletas olímpicos competitivos diz respeito ao reclame por uma "geração de esportistas"; e 3) de indigentes a heróis olímpicos, referindo-se ao papel desempenhado pelos brasileiros nos Jogos.

\section{"Ser olímpico"}

A reportagem “Os Olímpicos” (REVISTA VEJA, 1968, p. 49) apresenta um contexto que nos permite inferir a respeito de certa indefinição e/ou oscilação em relação ao sentido da participação dos brasileiros nos Jogos Olímpicos, especificamente, na transição da década de 1960 para 1970. O texto é extenso (ocupa uma página inteira, dividida em três colunas da seção de Esportes da revista), e tem início com informações acerca da participação anterior da equipe olímpica brasileira (Tóquio, 1964) e a repercussão dessa participação. Lê-se:

Quando os olímpicos brasileiros voltaram de Tóquio, em 1964, com um quinto lugar [...] o presidente da República, o Marechal Castelo Branco, ficou muito decepcionado. Houve até ameaça de inquérito Policial Militar para apurar os gastos e investigar as convocações dos 83 atletas (REVISTA VEJA, 1968, p. 49).

Segundo a revista, a partir dessa "decepção", o Comitê Olímpico Brasileiro (COB) cogitou só enviar ao México os atletas com "[...] resultados olímpicos, isto é, com alguma possibilidade de classificação até o sexto lugar" (REVISTA VEJA, 1968, p. 49). Tendo em vista que essa medida reduziria muito a participação brasileira, isso não se concretizou.

Esses relatos remetem a uma associação entre a excelência esportiva e a legitimidade política-internacional do país a partir de um dos maiores - senão o maior - eventos esportivos

\footnotetext{
${ }^{4}$ Constatamos que as reportagens eram publicadas sem a identificação ou assinatura dos autores dos textos. Observamos apenas a identificação dos fotógrafos, em caso de fotos acompanharem as reportagens. Portanto, ao longo do artigo a autoria de citações será indicada apenas pelo nome da revista.
} 
do mundo (DaCOSTA, 2000). Percebe-se, no entanto, que o discurso de autoridades políticomilitares daquele contexto (1964) mudam nos Jogos de 1968, atingindo uma aparente consonância com a meta ideológica do Movimento Olímpico.

Tal consonância refere-se ao sentido educativo do esporte, que é um fator muito importante para os propósitos ideológicos dos JO (TAVARES, 2003). Isso pode ser percebido na declaração do major Sylvio de Magalhães Padilha, então presidente do COB: “- Estamos quase desiludidos do apoio que temos pedido ao Ministério da Educação, para que ele adote outra orientação em relação à vida física do estudante" (REVISTA VEJA, 1968, p. 49).

O discurso de Sylvio Padilha ilustra uma preocupação com a população estudantil, de maneira a estar orientado por uma perspectiva dicotômica: o que é intelectual e o que é físico. Outro aspecto notório a partir dessa declaração é a organização político-administrativa em geral e, também, do esporte da época. Destaca-se que sucessivas declarações do major Padilha redimensionam o sentido da participação dos brasileiros, diferenciando-a da apresentação inicial da reportagem sobre os Jogos de 1964:

Ser Olímpico é o maior prêmio que um amador pode obter no Brasil. Nós abrimos mão da rigidez dos índices como um estímulo aos jovens que se dedicaram, apesar de todas as dificuldades e de sacrifícios incríveis, a fazer o esporte amador no Brasil (REVISTA VEJA, 1968, p. 49, grifo do autor).

Nota-se a clara menção à prática amadora do esporte relacionada ao sentido de "ser olímpico". É preciso esclarecer que o "amadorismo" citado na reportagem não se refere à "baixa qualidade" do esporte brasileiro quanto à performance (como antítese de profissional). O fato é que, por muitos anos, ser atleta "amador" era um critério de elegibilidade para participar dos Jogos Olímpicos. O amadorismo era então concebido como a prática do esporte - competição e treinamento - sem fins lucrativos (SENN, 1999) ${ }^{5}$.

Na reportagem "Aprender antes de competir" (REVISTA VEJA, 13 set. 1972, p. 68), sobre a participação brasileira nos Jogos de Munique (1972), foi possível identificar que a questão do amadorismo ainda se faz presente:

No dia em que o Brasil comemorava os 150 anos de sua independência, a bandeira do losango amarelo em campo verde pendia [...] de luto pela morte dos atletas israelenses assassinados [...] Mas, para o Brasil as Olimpíadas já pareciam ter terminado dois dias antes no momento em que Nelson Prudêncio ganhava sua medalha de bronze no salto triplo [...] A se acreditar nas declarações de alguns atletas, um colossal urubu pousou na sorte do esporte amador brasileiro ${ }^{6}$.

\footnotetext{
5 Apenas na década de 1980 que algumas abordagens históricas do esporte - como Young (1984) desmistificaram essa concepção, apontando para o amadorismo como um conceito que foi utilizado pelas elites inglesas no final do século XIX, de modo a fomentar a prática esportiva das elites, separada da classe trabalhadora. Nas décadas de 1970 para 1980 é que o conceito do amadorismo distorcido perdeu espaço nos Jogos Olímpicos.

${ }^{6}$ Grifo dos autores.
} 
Apesar do sentido amador do "ser olímpico" brasileiro, de certa maneira, houve uma oscilação no discurso da RV, sobretudo a partir da citação de declarações de autoridades político-administrativas do esporte. Tal oscilação consiste no fato de que, em certos momentos, enfatizou-se o sentido educativo do esporte para os jovens e, noutros, clamou-se por uma melhor preparação dos atletas brasileiros.

\section{O clamor por atletas olímpicos competitivos}

Apresentam-se, nesta seção, as principais características do "reclame" presente nas elaborações discursivas da RV por uma "melhor organização" do esporte olímpico brasileiro. É preciso atentar que tal "reclame" é, em vários momentos, realizado por autoridades cujas falas são utilizadas em citação direta na revista.

Vale ressaltar que no processo de construção de suas narrativas ("codificação"), as mídias escolhem representações que, de alguma forma, delineiam o viés institucional, ou seja, o "sentido preferencial" (HALL, 2003) que desejam embutir na mensagem. Nesse sentido, a menção a essas falas, sem posicionamento crítico subsequente, em reportagens "não assinadas", representam as escolhas da revista analisada, a partir das quais podem ser elaboradas diversas inferências.

A RV, apesar de mencionar o sentido do "ser olímpico", a partir da presença dos "amadores" brasileiros nos Jogos do México, apresenta, quatro anos mais tarde, na cobertura dos Jogos de Munique, outra perspectiva:

O dinheiro está aparecendo, mas a mentalidade não muda. E o esporte Nacional continua nas mãos do Ministério da Educação que já tem todo o ensino brasileiro - do Mobral aos cursos de pós-graduação - para cuidar. Em Munique, na volta para casa, pensa-se bem se não seria a hora de se olhar o esporte de nova maneira, visando menos a treinar um grupo de atletas para uma competição e mais a preparar gerações de esportistas (REVISTA VEJA, Aprender antes de competir, 1972, p. 72).

É possível notar que - embora em diversas citações a Revista Veja tenha apresentado narrativas sobre 1972 prezando a valorização da participação brasileira em Jogos Olímpicos há também narrativas que demonstram uma "sede" por mudanças na organização do esporte, possivelmente motivada pela ausência de resultados expressivos. Os discursos das autoridades da época e a visibilidade midiática que a RV atribuiu a eles não resultou em mudanças imediatas na organização do esporte no Brasil. O Ministério do Esporte - instituição especificamente responsável por promover e gerir o esporte no Brasil - foi criado muitos anos depois, em 1995.

É difícil precisar o sentido atribuído ao clamor por uma formação de "esportistas" no fragmento citado, pois ele pode remeter tanto à demanda por atletas mais competitivos, quanto à proposição de mudança no estilo de vida da população, ou, inclusive, ambos, numa relação causal.

Nas narrativas de 1976, o clamor por uma formação de "esportistas" também está presente. Há um quadro que ilustra as "poucas" conquistas dos brasileiros em 11 Olimpíadas, o qual é intitulado "Brasileiros: as medalhas ganhas por acaso": 
[...] o Brasil ganhou apenas dezesseis medalhas das quase 6000 disputas: três de ouro, duas de prata e onze de bronze. Mas essas medalhas praticamente caem do céu, mesmo nos esportes em que o país formou alguma tradição, como o salto triplo e o basquete. Tudo fica na dependência de surgirem personalidades excepcionais no quadro de atletas brasileiros (REVISTA VEJA, Olimpíada: o grande espetáculo, 1976, p. 114).

Tal análise pode indicar uma avaliação negativa, por meio do discurso de autoridades, em relação às condições de prática e desenvolvimento do esporte no Brasil, bem como sua representação internacional. Tendo em vista o "baixo" número de medalhas, as conquistas obtidas são associadas a eventualidades/casualidades.

De fato, na literatura antropológica brasileira sobre o esporte e os Jogos Olímpicos, encontra-se autores que atestam essa questão, o que indica que esse sentido de participação veio a prolongar-se. DaMatta (2003), por exemplo, situa o Brasil dentre os países que têm aspirações limitadas no evento, em termos competitivos. Em casos como esse, [...] "a ideia de participação se reduz a desempenhar um papel efetivamente legitimador no evento", o que significa, neste caso, "legitimar a vitória do outro" (DaMATTA, 2003, p. 184).

Na mesma reportagem, a análise da participação brasileira é inserida em um contexto um pouco mais amplo, o sul-americano. De certa maneira isso relativiza o fato de o Brasil não ser uma potência olímpica, demonstrando que esse é um problema presente em outros países mais próximos da realidade nacional:

Sinal da cruz - [...] sem técnica, sem equipamentos e preparação à altura dos melhores, resta, como alternativa, a esperança nos céus. Na beira das piscinas e das pistas, nadadores e atletas brasileiros - como de resto sulamericanos em geral - invariavelmente fazem o sinal da cruz. Sem grandes resultados [...] das 120 medalhas distribuídas, nenhuma tinha ido para qualquer país sul-americano (REVISTA VEJA, 1976, p. 113).

\section{De indigentes olímpicos ${ }^{7}$ a heróis nacionais}

Os Jogos de Moscou, em 1980, foram os primeiros a serem realizados em um país socialista. Esse fato, por si só, mereceu grande destaque, considerando que a Guerra Fria ainda não havia terminado. Com isso, o boicote americano ganhou força e a adesão de vários outros países, conhecidos por terem bons desempenhos esportivos, tais como Japão e China (SENN, 1999).

Na reportagem "A URSS e a olimpíada" (REVISTA VEJA, 1980, p. 46), analisa-se o impacto do boicote de americanos e outros países ocidentais sobre a competição ${ }^{8}$. As

\footnotetext{
${ }^{7}$ Esta é uma adaptação do termo cunhado em uma das narrativas da Revista, na década de 1980 (citada a seguir neste tópico).

8 O boicote aos Jogos de Moscou aconteceu de forma que os Estados Unidos, bem como outros países ocidentais, não compareceram com delegações nacionais oficiais ao evento (apesar de algumas delegações terem participado sob a bandeira olímpica) por divergências político-militares - para esclarecimentos, cf. Senn (1999), especialmente as páginas 173-189.
} 
narrativas sobre a participação brasileira, por sua vez, pareciam conformadas à posição coadjuvante de uma nação sem potências esportivas:

Para o Brasil, órfão da medalha de ouro que mais cobiçava nessa olimpíada - a do salto triplo - veio um prêmio de consolação das raias de Tallin. Foi nesse balneário da Estônia que o vento da vitória soprou para iatistas paulistas e cariocas, arrancando o país daquele velho grupo que nunca chega [...] Mas, foi uma vitória sem torcida, sem participação e, até mesmo, sem identificação nacional, dadas as características do iatismo no Brasil [...] De resto, o Brasil navegou por essa última semana olímpica entre a bravura do pobre a seriedade do competente (REVISTA VEJA, O fim da festa Russa, 1980 , p. 77 , grifo do autor).

Na mesma reportagem a associação do desempenho nos Jogos com a saúde e a educação é evidente:

De modo geral, mesmo conquistando, todos somados, menos medalhas que um único desportista russo [...] os 109 atletas brasileiros tiveram uma atuação condizente com o estado de saúde geral do país. Essa mesma média vigorou entre países menos educados no esporte, e que trouxeram para Moscou um volumoso contingente de pobres coitados [...] (REVISTA VEJA, O fim da festa Russa, 1980, p. 78-79, grifo do autor).

Esse tipo de narrativa remete a uma visão que alcançou, em determinado momento da história, a produção acadêmica, a qual relegava ao esporte uma função utilitarista e/ou funcionalista (com o higienismo e a visão orgânica de corpo), tal como aponta DaMatta (1982, p. 22).

Nos JO de 1984, o contexto político parece provocar certo otimismo nas narrativas da Veja. Com o boicote da União Soviética e de quase todos os países comunistas ${ }^{9}$, assume-se na narrativa que há melhores chances de medalhas para o Brasil em determinadas modalidades. Demonstra-se, com efeito, que importa atingir bons resultados nos Jogos, mesmo que para isso tire-se proveito de um cenário atípico:

A maior delegação já enviada pelo Brasil a uma Olimpíada - cerca de 150 pessoas - inclui desde praticantes de modalidades exóticas, como nado sincronizado, até esportes com os quais a torcida brasileira está familiarizada há muito tempo. E nestes, sobretudo após o boicote da União Soviética e quase todos os outros países comunistas, a equipe nacional efetivamente leva chance de obter medalhas, mais talvez que em qualquer outra olimpíada já disputada pelo Brasil (REVISTA VEJA, O Brasil decola para Los Angeles, 1984, p. 66).

Em vários trechos da reportagem, a Revista Veja refere-se aos Jogos de Los Angeles como "falsos" pela ausência de muitos atletas consagrados e importantes dos países que

\footnotetext{
${ }^{9}$ Boicote ocorrido em espécie de revanche ao boicote de 1980. Cf. nota 8.
} 
boicotaram os Jogos. Isso ocorre, porém, antes da realização dos Jogos. Com o melhor desempenho histórico obtido até então, o discurso da Veja muda e emudece o questionamento sobre a legitimidade e credibilidade dos Jogos, levando a crer que as medalhas conquistadas pelos atletas brasileiros não foram porque eles eram os melhores dentre os poucos presentes em Los Angeles, mas porque eles eram os melhores do mundo:

Nunca tantos atletas subiram ao pódio em tão poucos dias, nunca o país se comoveu de forma tão aguda com a atuação de seus representantes nos estádios e nos ginásios, e nunca houve uma colheita tão grande de medalhas [...] de longe o melhor desempenho numa olimpíada desde a primeira que o Brasil participou, em 1920. Sobretudo, nunca o Brasil pressentiu com tamanha nitidez que os tempos de indigência olímpica podem estar chegando ao fim (REVISTA VEJA, Ouro! A grande olimpíada brasileira, 1984, p. 46, grifo do autor).

No trecho acima, percebe-se que os dados sobre o boicote e a ausência de renomados atletas competindo em várias modalidades são ignorados, em função de ressaltar os feitos dos atletas que representaram o Brasil. $\mathrm{O}$ trecho em destaque remete também à ideia de que a participação com êxito da delegação brasileira pode levar a mudanças na atenção dada ao esporte e/ou ao evento Olímpico em si. Esse tipo de narrativa preponderou na cobertura da revista no final dos Jogos de Los Angeles e em referência aos Jogos de Seul, no ano de 1988, na reportagem "Arrancada para Seul", em que a expectativa de uma iminente mudança permanece. Destaca-se a comparação entre o atleta e o cientista para explicar o orgulho nacional que uma vitória pode simbolizar:

Muita torcida, poucas medalhas. Costuma ser essa a realidade do Brasil na Olimpíada. Por isso mesmo, cada medalha vem regada a alegria dupla, no país. Como um cientista premiado com o Nobel, um atleta que ganha uma medalha de ouro nos Jogos Olímpicos, mesmo que tenha treinado no exterior, é um produto da cultura de seu povo e por isso todos sentem-se de certa forma premiados (REVISTA VEJA, 24 ago. 1988, p. 74).

Os Jogos de 1992 foram sediados em Barcelona. Em estratégia editorial similar àquelas utilizadas nas narrativas de 1988, os atletas brasileiros com chances de bons resultados foram apresentados ao público em matérias especiais que enfatizavam o histórico dos mesmos, suas habilidades e pontos fortes, criando expectativas sobre possibilidades de conquistas de medalhas. As narrativas publicadas após o evento também seguem o modelo dos anos 1980, enfatizando a imagem vencedora do país e ignorando os maus resultados. Um resumo com os momentos de maior destaque no contexto internacional encerra as narrativas do pós-Jogos e ocupou 20 páginas de uma mesma edição.

Os atletas vitoriosos foram retratados como heróis e suas histórias de vida foram densamente exploradas e descritas, geralmente enfatizando narrativas de superação de adversidades, atribuindo grandeza às vitórias etc. Tal característica faz parte do processo de produção de ídolos tipicamente presente no discurso midiático sobre o esporte de alto rendimento, como já verificado em outros estudos, por exemplo, Santos e Medeiros (2009).

As reportagens pré-evento sobre os Jogos de Atlanta (1996) apresentaram, com maior ênfase, as qualidades dos atletas brasileiros. A fórmula inaugurada na edição de 1988 sobre 
explorar em matérias as histórias de vida e profissionais dos atletas se repetiu. O volume de informações publicadas antes da realização dos Jogos aumentou:

[...] Para o Brasil, a chance de sair de seu modesto perfil Olímpico acanhado - com medalhas em no máximo 3 esportes diferentes - é real. Jamais o país se apresentou com uma equipe olímpica forte em tantos esportes [...] (REVISTA VEJA, Arranca Brasil, 1996, p. 40).

As expectativas se confirmaram e a delegação brasileira obteve os melhores resultados de sua história até então. As narrativas posteriores ao evento também seguiram o modelo inaugurado em 1988, enfatizando o contexto internacional e apresentando, em detalhes, as histórias dos medalhistas em narrativas enaltecedoras.

O Brasil simplesmente mudou de patamar no universo esportivo [...] O país superou em muito a série de oito medalhas históricas conquistadas nos Jogos de Los Angeles, até então o recorde brasileiro. O Brasil saiu em números de medalhas, um país mais vigoroso esportivamente do que a Inglaterra, Bélgica ou o Canadá. O que não deixa de ser assombroso mesmo sabendo que saúde esportiva não se traduz apenas por medalhas (REVISTA VEJA, Com o Brasil no peito, 7 ago. 1996, p. 98).

A importância dos Jogos como um palco para legitimação política e/ou econômica é implicitamente evidenciada na comparação do Brasil com países do "primeiro mundo". O contexto da década de 1990 perpassa também o interesse organizacional sobre os Jogos, pois foi também durante esse período que o Comitê Olímpico Brasileiro primeiro elaborou um projeto para sediar os Jogos Olímpicos (RUBIO, 2010). Logo após os Jogos de 1996, o COB começou um novo projeto para candidatar o Rio de Janeiro como a cidade-sede para 2004. O projeto, desde então, foi renovado e remodulado para a candidatura de $2012 \mathrm{e}$, finalmente, 2016.

\section{Considerações finais}

No decorrer das análises foi possível observar as mudanças com que os atletas olímpicos brasileiros foram retratados ao longo da história, assim como o próprio evento. $\mathrm{Na}$ década de 1960 percebe-se a insatisfação das autoridades brasileiras com os resultados obtidos nos Jogos de 1964, ao mesmo tempo - e paradoxalmente - em que se buscou legitimar a participação brasileira através do sentido de "ser olímpico", que, de certa forma, coincide com um dos princípios ideológicos do Movimento Olímpico.

Embora o sentido de "ser olímpico" legitimasse a participação dos atletas brasileiros nos JO, havia um clamor por melhores resultados, expresso principalmente nas reportagens da década de 1970 (Jogos de Munique, 1972; Montreal 1976). A ânsia por conquistas mais expressivas perpassou por discursos que enfatizavam uma mudança necessária na organização esportiva no Brasil.

Durante a década de 1980, os boicotes aos Jogos de Moscou (1980) e Los Angeles (1984) causaram uma oscilação nas narrativas da revista que, num primeiro momento, descredenciavam os Jogos pela ausência de atletas consagrados e, num segundo momento, após a maior conquista de medalhas até então (Jogos de Los Angeles), os atletas brasileiros 
são consagrados como heróis nacionais. A partir deste feito olímpico, as narrativas passaram a abordar com otimismo o esporte brasileiro e a participação nos Jogos. Assim, as reportagens da década de 1990 adotam a ênfase nas conquistas dos atletas e ignoram os maus resultados.

De fato, os Jogos Olímpicos, tanto em sua forma materializada quanto ideológica, produz múltiplas possibilidades de produção, articulação, veiculação e consumo de narrativas midiáticas. A análise dos Jogos e suas multidimensões, tanto a partir de uma perspectiva "performática" quanto "discursiva", pode permitir captar (pontual e processualmente) os impactos que este evento tem sobre a sociedade brasileira, no que se refere à política, à economia, à educação, à Educação Física e ao esporte, dentre outras facetas da esfera social.

\title{
OLYMPIC GAMES IN MAGAZINE: A STUDY OF BRAZILIAN PARTICIPATION IN THE OLYMPIC GAMES (1968-1996)
}

\begin{abstract}
This study aims to analyze media narratives about the Olympics from materials and/or stories published in Revista Veja from 1968 to 1996. For doing so, the Content Analysis method were used. The following thematic classes were identified and discussed: 1) being an Olympian - related to Brazilian amateur participation; 2) the claim for competitive athletes - corresponding to demands for better sport organization and perfomances; 3) from "indigent" to Olympic heroes - narratives that link the changing role of Brazilian participation, emphasizing good results.
\end{abstract}

Keywords: Sport. Media. Olympics.

\section{JUEGOS OLÍMPICOS EN REVISTA: UN ESTUDIO DE LA PARTICIPACIÓN DE BRASIL EN LOS JUEGOS OLÍMPICOS (1968-1996)}

\begin{abstract}
Resumen
Este estudio tiene como objetivo analizar las narrativas de medios sobre juegos olímpicos, a partir de reportajes de la Revista Veja, de 1968 a 1996. Para tanto, se utilizó como técnica el Análisis de Contenido. Los siguientes temas fueron identificados y discutidos a partir de las narrativas: 1) ser "Olímpico" en referencia al sentido de la participación aficionada de los brasileños; 2) el clamor por atletas competitivos correspondiendo a el cobro por una mejor organización y resultados deportivos; 3 ) de "indigentes" a héroes olímpicos - narrativas que vinculan el papel cambiante de la participación de Brasil, enfatizando los buenos resultados.
\end{abstract}

Palabras clave: Deporte. Media. Juegos Olímpicos.

\section{Referências}

BARNEY, R. K.; WENN, S.; MARTIN, S. G. Selling the Five Rings: the International Olympic Committee and the Rise of Olympic Commercialism. Salt Lake City: University of Utah Press, 2002.

BAUER, M. W.; GASKELL, G. (Org.). Pesquisa qualitativa com texto, imagem e som. Tradução de P. A. Guareschi. Petrópolis: Vozes, 2002. 
BRIGGS, A.; BURKE, P. Uma história social da mídia: de Gutenberg à internet. Trad.Maria Carmelita Pádua Dias. Rio de Janeiro: Jorge Zahar, 2004.

DaCOSTA, L. P. Olympic Studies: current intelectual crossroads. Rio de Janeiro: Gama Filho, 2000.

DAMATTA, R. Em Torno da Dialética entre Igualdade e Hierarquia: Notas sobre as Imagens e Representações dos Jogos Olímpicos e do Futebol no Brasil. Antropolítica (UFF), Rio de Janeiro, v. 1, n. 14, 2003.

DAMATTA, R. Esporte na sociedade: um ensaio sobre o futebol brasileiro. In: (Org.). Universo do futebol. Rio de Janeiro: Pinakotheke, 1982. p. 19-42.

ELIAS, N.; DUNNING, E. A busca da Excitação. Lisboa: Difel, 1992.

GUTTMAN, A. The Games Must Go On: Avery Brundage and the Olympic Movement. New York: Columbia University Press, 1984.

HALL, S. Da diáspora: identidade e mediações culturais. Belo Horizonte: Editora Universidade Federal de Minas Gerais, 2003.

MACALOON, J. B. Olympic Games and the theory of Spectacle. In: (Org.). Rite, drama, festival, spectacle: rehearsals toward a theory of cultural performance. Philadelphia: Institute for the study of Human Issues, 1984.

Revista Veja. Os Olímpicos. São Paulo, 3. ed., p. 48-49, set. 1968.

Revista Veja. Aprender antes de competir. São Paulo, 210 ed., p. 68-72, set. 1972.

Revista Veja. Olimpíada: o grande espetáculo. São Paulo, 412 ed., p. 108-114, jul. 1976.

Revista Veja. A URSS e a olimpíada. São Paulo, 620 ed., p. 46-50, jul. 1980.

Revista Veja. O fim da festa Russa. São Paulo, 622 ed., p. 77, ago. 1980.

Revista Veja. O Brasil decola para Los Angeles. São Paulo, 821 ed., p. 66, mai. 1984.

Revista Veja. Ouro! A grande olimpíada brasileira. São Paulo, 832 ed., p. 46-66, ago. 1984.

Revista Veja. Arrancada para Seul. São Paulo, 1042 ed., p. 74-80, ago. 1988.

Revista Veja. Com o Brasil no peito. São Paulo, 1456 ed., p. 98-110, ago. 1996.

Revista Veja. Arranca Brasil. São Paulo, 1454 ed., p. 40-44, 1996.

RUBIO, K. Postulações brasileiras aos Jogos Olímpicos: considerações acerca da lenda do 
distanciamento entre política e movimento olímpico. Revista Bibliográfica de Geografía Y Ciencias Sociales, Universidad de Barcelona, 2010.

SANTOS, D.; MEDEIROS, A. G. A. O discurso midiático e as representações sociais do esporte: o atleta como modelo de comportamento. Pensar a Prática, Goiânia, v. 12, n. 3, nov. 2009.2 Disponível em: <http://www.revistas.ufg.br/index.php/fef/article/view/6937/6191>. Acesso em: 29 set. 2013.

SENN, A. E. Power, Politics and the Olympic Games. Champaign: Human Kinetics, 1999.

SPÀ, M. DE M. The mass media, Olympic values and the opening ceremony. In: BYONGIK, K. (Ed.). Toward one World, beyond all barriers: Keynote speeches; cultural exchange and cultural nationalism. The Seoul Olympiad Anniversary Conference. v. 1, 1990. [Seoul]: Poong Nam. p. 455-473. Disponível em: $<$ http://www.dyu.edu.tw/ osc/olympic/con_htm/c2pdf/c2023.PDF>. Acesso em: 30 maio 2011.

TAVARES, O. Esporte, Movimento Olímpico e Democracia: o atleta como mediador. Tese (Doutorado em Educação Física). Universidade Gama Filho, Programa de Pós Graduação em Educação Física, Rio de janeiro, 2003.

YOUNG, D. C .The Olympic Myth of Greek Amateur Athletics. Chicago: Ares Publishers, 1984.

Recebido em: 12/10/2014

Revisado em: 14/04/2015

Aprovado em: 06/08/2015

Endereço para correspondência:

dsilvado@uwo.ca

Doiara Silva dos Santos

Universidade Federal de Juiz de Fora, Faculdade de Educação Física.

33333

São Pedro

35020-220 - Governador Valadares, MG - Brasil 